\title{
Research on Construction Schedule Control and Management Based on Particle Swarm Optimization
}

\author{
Youren Liu ${ }^{1,2^{*}}$, Zub A.T. ${ }^{1}$ \\ ${ }^{1}$ Faculty of State Management, Lomonosov Moscow State University, Moscow 119991, Russia \\ ${ }^{2}$ Power Construction Corporation of China, Beijing 100048, China \\ *Corresponding Author.
}

\begin{abstract}
Project management is to use scientific theories and methods, and coordinate to achieve the objectives of project establishment. It must be clearly seen that there are many problems in the management of construction enterprises in China, and the management level of construction projects is not uniform. The whole process of building construction is the process of putting in labor, building materials and technical methods to produce building products that meet the requirements. As an enterprise, it must consider its own economic benefits. Different projects can be divided into several stages with different contents and numbers according to specific conditions. The results of the operation of the project management activities are significant or not, and become the key to whether the construction enterprise construction project group can generate enterprise benefits. Based on the particle swarm optimization algorithm, this paper provides some references for such project management by discussing the relationship between construction schedule and economic benefit, construction schedule and quality management. We should conduct in-depth and systematic research on China's project management model and organizational environment, and try to better suit the project management operation mechanism of China's national conditions.
\end{abstract}

Keywords: Project Management, Construction Enterprise, Construction Progress, Particle Swarm Optimization

\section{Introduction}

Construction enterprises are facing fierce market competition and whether they can remain invincible in the competition depends on whether they can provide high-quality, short-term and low-cost construction products for the society [1]. Project management is to use scientific theories and methods, and coordinate to achieve the objectives of project establishment. To plan, organize, direct, control and coordinate the objectives of the project [2]. Construction enterprises are facing enormous challenges, how to use limited resources to manage different functional building groups at the same time, to achieve the economic benefits of construction enterprises [3]. It must be clearly seen that there are many problems in the management of construction enterprises in our country, and the management level of construction projects is good and rash [4]. As a traditional engineering construction field that implements project management, in recent years, great progress has been made in engineering project management theory and practice. Construction project schedule management can effectively control the input of project labor, machinery and materials [5]. The whole process of building construction is to invest labor, building materials, mechanical equipment and technical methods to produce the building product process that meets the requirements, and is also the organizational process of the production elements of building products [6]. Construction companies focus on the management of large-scale projects from a management level and a technical level.

The construction industry has a high degree of correlation and a large employment capacity. It is an important production sector of the national economy and a pillar industry of the national economy. The progress management of modern construction projects is to integrate the progress management and cultural management into the construction process under the conditions of dynamic implementation of the construction project [7]. The project is

ISSN: 0010-8189

(C) CONVERTER 2020 
carried out in a complex natural and social environment. This is a process full of uncertainty, and the implementation of the project is constrained by time, resources and environment [8]. The project progress management level is one of the comprehensive indicators to measure the management level of construction enterprises. Project schedule management is an important part of project management of construction enterprises [9]. Whether the operation results of project group management activities are significant or not has become the key to whether the construction enterprise can produce enterprise benefits. The construction unit shall, in accordance with the contract or agreement, make careful calculations and construct carefully [10]. As an enterprise, it must consider its own economic benefits. Under the market economy system, some construction enterprises with poor management level and lack of management methods will inevitably lead to the current situation of high cost, weak on-site management and poor efficiency of construction projects [11]. Great changes have taken place in the construction industry, and the fierce competition has intensified, which has led to the transformation of enterprise competition to institutional competition and management competition.

Project management is a new management science, which is the product of the combination of modern engineering technology and practice, management theory and project construction practice [12]. The project plan is the concrete embodiment of the content of the project implementation, which forms the basis of the whole project. Project planning needs to be formulated through certain project management tools and methods, and the corresponding project team is responsible for the implementation of [13]. Driven by the characteristics of large-scale and complex construction projects, construction qualification standards are improved. Enterprises with high construction qualification of construction projects often undertake multiple projects at the same time, and carry out collaborative management of projects [14]. It must be clearly seen that there are many problems in the management of current construction enterprises in China, and the management level of construction projects is mixed. In the era of today's projects, project management is not only an effective method for managing large-scale and complex projects, but also an important method for enterprise management in the century [15]. Different projects can be divided into several stages with different content and number according to the specific situation. In order to meet the infrastructure functional needs of residents, construction projects have gradually transitioned to large projects [16]. Based on the particle swarm optimization algorithm, this paper provides some references for such project management by discussing the relationship between construction schedule and economic benefit, construction schedule and quality management. Really take project management as a holistic, process-wide process.

In this article, we propose a research method based on particle swarm optimization algorithm, which is aimed at the research on construction project construction schedule control and management.

In summary, our contributions are as follow:

1. Particle swarm optimization algorithm is a random search algorithm based on group collaboration developed by simulating the foraging behavior of birds.

2. The paper proposes a particle swarm optimization model for construction project construction schedule control and management.

3. This technology has good computational efficiency in the research of construction project construction schedule control and management, and has reliable calculation results for most construction schedule control and management problems.

\section{Related Work}

Maalek R et al. mentioned in the article "Robust Classification and Segmentation of Planar and Linear Features for Construction Site Progress Monitoring and Structural Dimension Compliance Control" that a project is created by creating a unique product or service under certain resource constraints. One-time effort [17]. The project has the characteristics of one-time, unique, conflicting and life-cycled. It is the ideal of every investor to minimize the engineering construction cycle in today's fierce market competition. Guenet E believes that project management is

ISSN: 0010-8189

(C) CONVERTER 2020

www.converter-magazine.info 
one of the main trends in project management development, and it is a new management model based on the management of single project combined with organizational strategy management [18]. Wang $\mathrm{H}$ et al. proposed that during the construction of the construction project, there are characteristics of large capital investment and complex construction [19]. Compared with single project management, project group management has complex organizational structure. $\mathrm{Xu} \mathrm{H}$ analysis considers that the human behavior characteristics are fully taken into account in the project schedule, and puts forward the hypothetical model conditions of low-risk estimation of project duration, project manager's safety boundary and project manager's protection to prevent global time reduction [20]. Professor Gavrilin A V pointed out that the process of optimizing the combination of production factors and resources owned or possibly available by an enterprise as a whole [21]. Its essence is the systematic collaborative innovation behavior under the guidance of enterprise strategy and constrained by organizational and technological factors.

\section{Materials and Methods}

Project management is to use the system's viewpoints, methods and theories to effectively manage all the work involved in the project under the constraints of limited resources. The purpose of the construction project planning is to systematically control the progress of the construction project. First, a master control plan must be prepared, that is, the overall schedule of the construction project. The preparation of the schedule begins with a job definition, which lists all the work lists needed to complete the project and sorts the work. Progress control is based on a reasonable and economical project schedule that has been developed in advance during a defined period of time. And the behavioral process of supervising, inspecting, guiding and correcting the entire construction process [22]. Projects are done rather than planned, so it's better to start working than to spend time planning. It's interesting that such people don't have enough time to plan, but they always have time to rework. The process of schedule refinement is also the process of target decomposition of schedule control. Through the decomposition of the progress plan layer by layer, the control of the overall progress goal of the construction project is guaranteed.

The basic theory of project group and schedule management mainly analyses the connotation and characteristics of project group, the connotation of project group management and the method of schedule management. Making a project plan is one of the reasons why many people are unwilling to make a plan because they need to consider and answer many questions. The pain curve points out that it is painful to plan a project, but it will reduce the pain in the implementation process and later stages of the project. The pain curve of project management life cycle is shown in Figure 1.

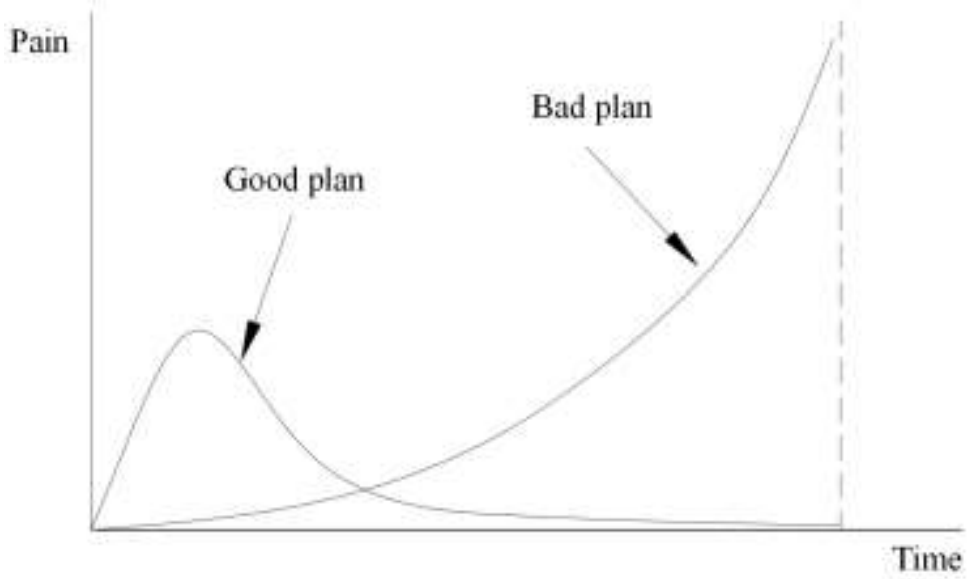

Figure 1 Project Management Life Cycle Pain Curve

Project management stems from practice and changes are made in the characteristics of practice to meet the various needs in practice. The project has implemented its essence to seek a relatively optimal process under the conditions of mutual constraints and conflicts or requirements in the project process. Different levels of responsibility have

ISSN: 0010-8189

(C) CONVERTER 2020 
different responsibilities for the progress control of construction projects, and the implementation content is different. The project phase is marked by milestones. The schedule should fully reflect the role of the milestones and determine the completion time of the project phase according to the reverse schedule method [23]. The owner or supervisor must carefully review the overall construction schedule prepared by the contractor, the unit construction schedule, etc. [24]. Project schedule management is an important aspect of project management. It is equivalent to project cost management and project quality management as an important part of project management. The construction project group gathers the characteristics of the project group and the construction, and takes the construction project as the object, carries on the multi-project combination. Information feedback is the key link of construction project progress management, which is based on division of labor and cooperation, the feedback progress information needs to be sorted out and analyzed.

In the design stage, the construction drawings can be continuously deepened and optimized, so as to achieve the goal of Engineering design. Analytic Hierarchy Process (AHP) is used to judge the impact of each sub-project on the cost importance of the two-storey underground project. As shown in Table 1, the budgetary amount of each material for the project.

Table 1 Project material budget

\begin{tabular}{|c|c|}
\hline Entry name & Budget (10,000 yuan) \\
\hline Architectural Engineering & 912.5 \\
\hline Plumbing & 142.8 \\
\hline Decoration Engineering & 91.1 \\
\hline Electrical Installation Engineering & 115.3 \\
\hline
\end{tabular}

The purpose of developing a project schedule is to control project time and save time. One of the main features of the project is the strict time limit requirements. A reasonable and scientific project construction plan is an extremely important part when the project begins to implement progress. Moreover, some time processes are estimated based on previous construction projects of the construction company. In the current construction schedule planning process, the plan review technique is based on an estimated time of $80 \%$ completion rate. The time estimate of the construction period is in accordance with the particle swarm optimization probability function, as shown in Figure 2.

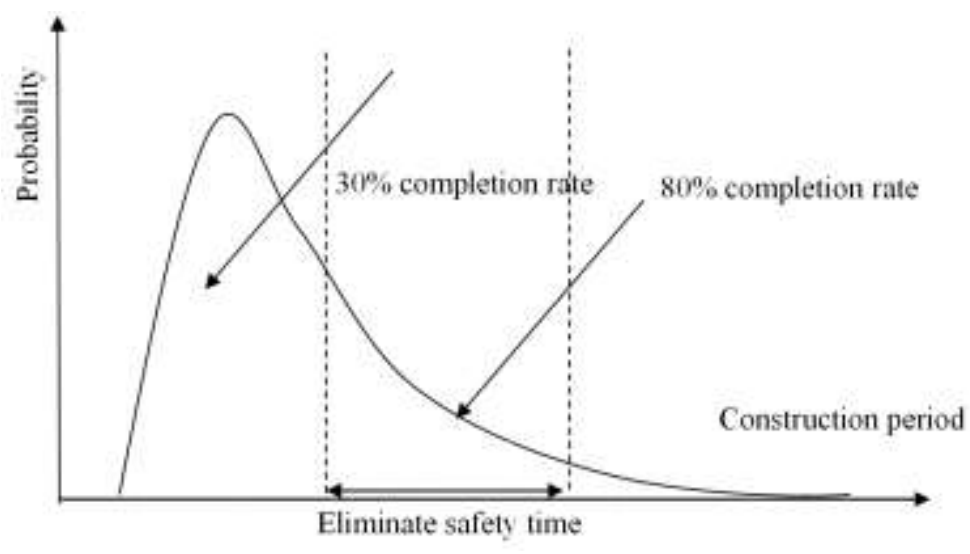

Figure 2 Estimated probability distribution of process duration

When the input vector of the particle swarm optimization model is determined, the distribution of the variables is checked, and the data needs to be transformed to facilitate the learning of the network. For variables that are continuous, the more common normalization methods are: 


$$
\mathrm{I}=\frac{24 \pi^{2} \mathrm{~A}^{2} \gamma \mathrm{V}^{2}}{\lambda^{4}}\left(\frac{\mathrm{n}_{1}^{2}-\mathrm{n}_{2}^{2}}{\mathrm{n}_{1}^{2}+2 \mathrm{n}_{2}^{2}}\right)^{2}
$$

The network convergence time is greatly shortened, and the performance of the network is improved. The transformation method is:

$$
\frac{\Pi}{\mathrm{c}}=\frac{\mathrm{RT}}{\overline{\mathrm{M}_{\mathrm{n}}}}+\mathrm{A}_{2} \mathrm{c}
$$

Use existing technology to create a multi-modal collaborative work environment. Find the heat transfer coefficient:

$$
\mathrm{u}=\frac{\xi \varepsilon \mathrm{E}}{\mathrm{k} \pi \eta}
$$

In order to ensure the efficiency of construction materials and reduce the project cost, the project management personnel must strengthen the management of the materials and their use on the construction site and strictly control them. A collaborative work support platform with an integrated and integrated multimedia model. The cooperative design operation process is shown in Figure 3.

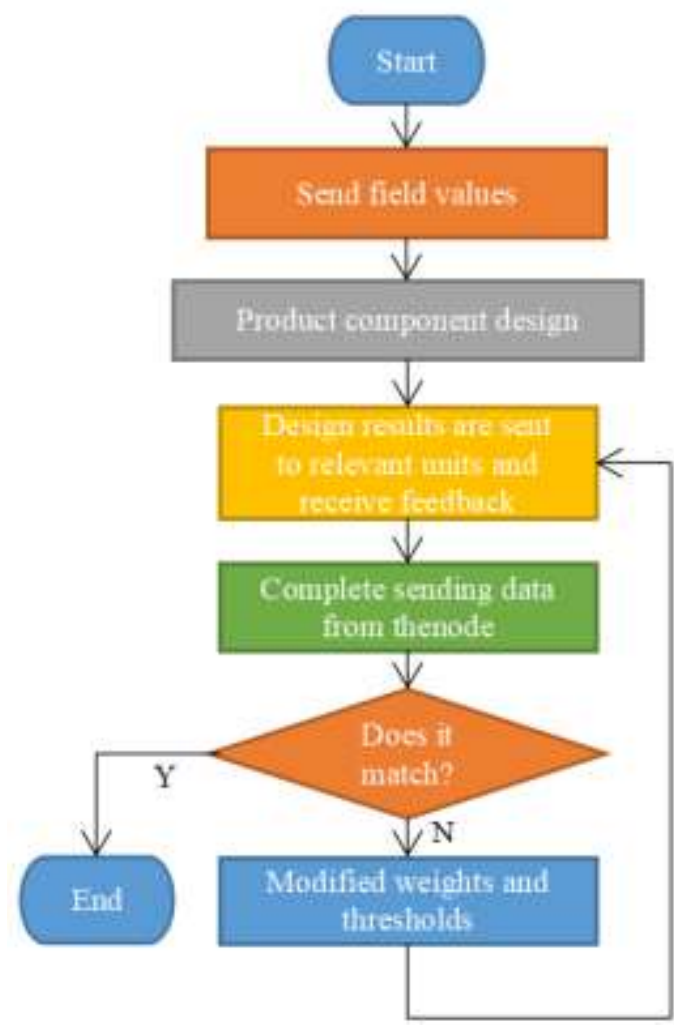

Figure 3 Construction engineering cooperation design operation process

Project schedule management refers to the management of the progress level of each stage and the final completion time of the project during the project implementation process. The process duration is subject to a lognormal distribution. The particle swarm optimization algorithm is used for normalization. Figure 4 shows the results of the key chain method planning. 


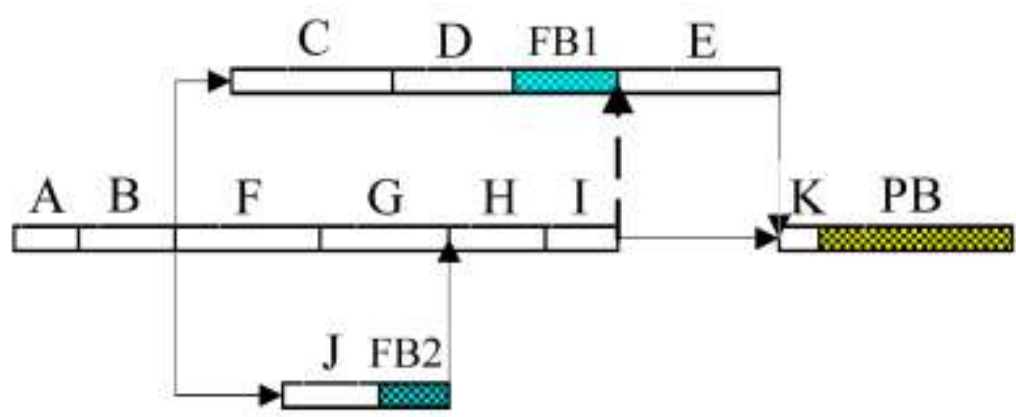

Figure 4 Key chain planning results

Discussing the construction project group from the organizational framework, mainly the construction project group is a way to cluster multiple projects based on an organizational strategy of the enterprise. The creation of building models based on particle swarm optimization algorithm can advance the design problems and quality problems that may occur in the project in the form of collision detection. See Table 2 for optimization of residential layout optimization performance parameters before and after optimization.

Table 2 Performance parameters of residential layout optimization topology before and after optimization

\begin{tabular}{|c|c|c|}
\hline & Before optimization & After optimization \\
\hline Row number & 18 & 26 \\
\hline Column number & 19 & 25 \\
\hline Monitoring points & 342 & 650 \\
\hline
\end{tabular}

In the building information model, extract and transform based on specific information formats to realize data docking and sharing between different professional software. Dimension processing of comparison series and reference series. In this paper, the mean method is used:

$$
\mathrm{D}=\frac{\mathrm{RT}}{\mathrm{L}} \frac{1}{6 \pi \eta \mathrm{r}}
$$

Under the interference of new factors, it is possible to generate new deviations, and continue to control according to the above methods:

$$
\mathrm{r}=\mathrm{k}_{2} \theta_{\mathrm{A}} \theta_{\mathrm{B}}=\frac{\mathrm{k}_{2} \mathrm{a}_{\mathrm{A}} \mathrm{a}_{\mathrm{B}} \mathrm{p}_{\mathrm{A}} \mathrm{p}_{\mathrm{B}}}{\left(1+\mathrm{a}_{\mathrm{A}} \mathrm{p}_{\mathrm{A}}+\mathrm{a}_{\mathrm{B}} \mathrm{p}_{\mathrm{B}}\right)^{2}}
$$

In the model, the topological relationship between two objects is characterized by whether the inner, outer and outer subsets of the object intersect, expressed as:

$$
\mathrm{r}=\frac{\mathrm{k}_{2} \mathrm{a}_{\mathrm{A}} \mathrm{p}_{\mathrm{A}}}{1+\mathrm{a}_{\mathrm{A}} \mathrm{p}_{\mathrm{A}}+\mathrm{a}_{\mathrm{B}} \mathrm{p}_{\mathrm{B}}}
$$

Project schedule control is continuously carried out as the project progresses. It is a dynamic process and a cyclical process. In the overall management of the project schedule, it is an overall process to strengthen the time schedule management and coordinate the implementation progress so that the project can be completed according to the expected quality and quantity. On the basis of comparative analysis, the project leader makes decisions, formulates reasonable measures to grab work or adjust the original construction schedule. The definition of project group management has a high starting point and is guided by organizational strategy and common goals. Schedule control is a dynamic cycle control method. Management is to accomplish a task through others, but this understanding is incomplete. Because it only emphasizes the right of management and neglects the initiative and initiative of others.

\section{Result Analysis and Discussion}

The project schedule is the implementation schedule arranged in a reasonable order, aiming at the completion,

ISSN: 0010-8189

(C) CONVERTER 2020

www.converter-magazine.info 
commissioning or delivery time of the proposed project according to the actual conditions and contract requirements. Only in this way can we form a strong control system of progress control. Organizational measures mainly refer to the establishment and improvement of progress control system and mechanism, and the clarification of the responsibilities and control points of managers at all levels. Aiming at the lagging design of side design and side construction engineering drawings, the focus of project management is also the solution of design drawings. Project schedule control is an ongoing dynamic control, but also a cycle process. Different personnel have different responsibility for progress control, division of labor and cooperation, forming a vertically and horizontally linked project progress control system. It is often because of the underestimation of the strength of the opponents or the rationality of the opinions, which has brought irreparable huge losses to the subsequent implementation of the project. The management of the project must have a common aspect, and overall management can produce greater benefits than the sum of each individual management benefit. Reasonable planning of logical relationships, resource conditions, and project schedules based on a complete schedule of tasks is the basis for implementing project management.

Architectural engineering modeling considers the physical properties of an object when modeling. Fractal technology and particle systems are typical physical modeling methods. Fractal techniques can describe data sets with self-similar features. Figure 5 shows the performance comparison results of the algorithm before and after storage optimization.

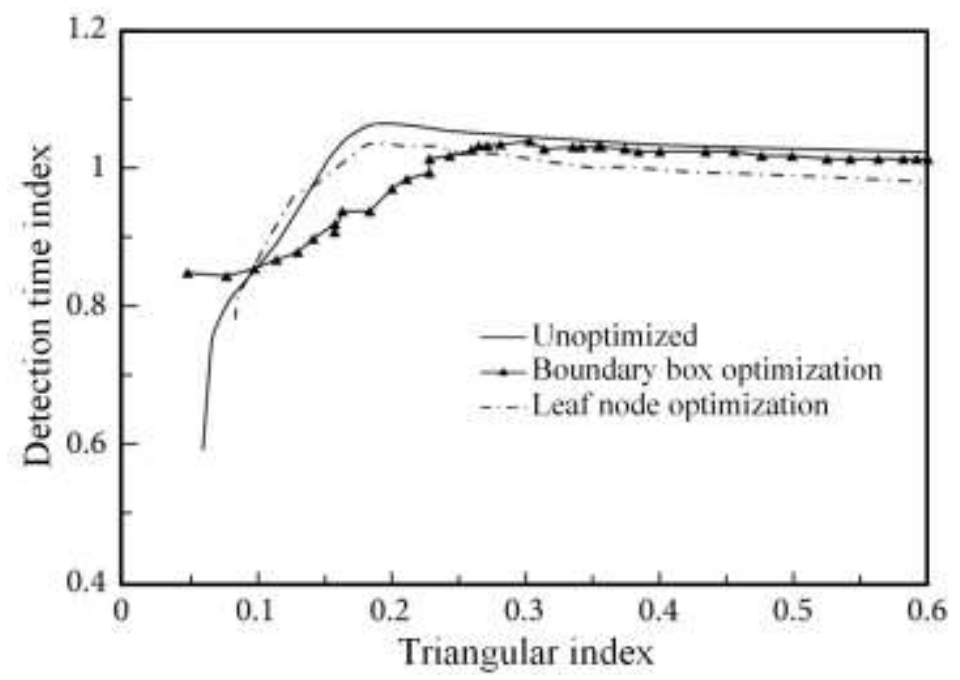

Figure 5 Comparison of algorithm performance before and after storage optimization

The training and learning process of the building model is the process of gradually decreasing the error value between the output value and the expected value of the network until the error meets the requirements. Definition error:

$$
\mathrm{V}=\mathrm{V}_{\mathrm{m}} \frac{\mathrm{Cp}}{\left(\mathrm{p}_{\mathrm{s}}-\mathrm{p}\right)\left[1+(\mathrm{C}-1) \frac{\mathrm{p}}{\mathrm{p}_{\mathrm{s}}}\right]}
$$

Apply it to the optimization of architectural engineering layout. The following formula:

$$
\mathrm{Wc}=-\Delta \mathrm{G}=2 \gamma_{\mathrm{g}-1}
$$

The particle speed is updated as follows during the run:

$$
\theta_{\mathrm{i}}=\frac{\mathrm{a}_{\mathrm{i}} \mathrm{p}_{\mathrm{i}}}{1+\sum_{1}^{\mathrm{i}} \mathrm{a}_{\mathrm{i}} \mathrm{p}_{\mathrm{i}}}
$$

In order to implement schedule control for the project, it is necessary to first prepare various schedules for the

ISSN: 0010-8189

(C) CONVERTER 2020 
project. When the technical department finds that the progress is lagging, in addition to preparing the progress control report, it is necessary to adjust the construction schedule according to the results of the regular meeting analysis. Information feedback is the main link of project schedule control. The actual progress of the project is fed back to the staff of the grassroots project schedule control through information feedback. The project has a long construction period and many influencing factors. In view of the characteristics of many subcontracting units and many construction personnel, the project has formed a three-level schedule management system [25]. This requires planners to estimate the extent and likelihood of various factors based on statistical experience and to analyze the target's risk when determining progress targets. One of the important reasons for the negative voices in making project plans is that the implementation plan of the project is not unique. Although the management of project group originates from project management in theory, it is higher than project management in management scope or management strategy. Each task in the progress plan has a clear division of responsibilities, and each department, department and specialty is responsible for its duties and responsibilities. If the principle of information feedback is not applied and the information feedback is continuously carried out, the planning control can not be carried out.

In building construction particle swarm optimization calculation, the calculation and analysis of the whole structure are carried out. According to the parameters of artificial seismic wave, the elastic time history analysis under multiple earthquakes is carried out. For example, Table 3 shows the maximum acceleration and duration of seismic waves.

Table 3 Maximum acceleration and duration of seismic waves

\begin{tabular}{|c|c|c|c|c|c|}
\hline $\begin{array}{c}\text { Adaptive } \\
\text { range }\end{array}$ & $\begin{array}{c}\text { Maximum } \\
\text { acceleration } \\
\text { value }\left(\mathrm{cm} / \mathrm{s}^{2}\right)\end{array}$ & Duration (s) & Wave number & Time step (s) & $\begin{array}{c}\text { Effective } \\
\text { duration (s) }\end{array}$ \\
\hline $\begin{array}{c}\text { Artificial } \\
\text { shock wave }\end{array}$ & 85 & 40 & 1780 & 0.04 & 32.43 \\
\hline $\begin{array}{c}\text { Natural shock } \\
\text { wave }\end{array}$ & 81 & 33 & 1859 & 0.03 & 34.51 \\
\hline
\end{tabular}

Facing the voice of opposition, we should pay due attention to it, recognize the problems it reflects and overcome them. When a person is not very clear about a job, he may neglect many details when estimating its workload and duration, so that the estimates deviate from reality. A steel bar obstruction similar to a structure is arranged at the position before receiving material or pumping to pass at the required speed. Concrete that does not pass through the device normally is considered to be unsuitable for filling. The ambient temperature and humidity of the concrete have an important influence on its strength development. The high curing temperature can accelerate the initial hydration speed and increase the initial strength of the concrete. The effect of curing temperature on concrete strength is shown in Figure 6.

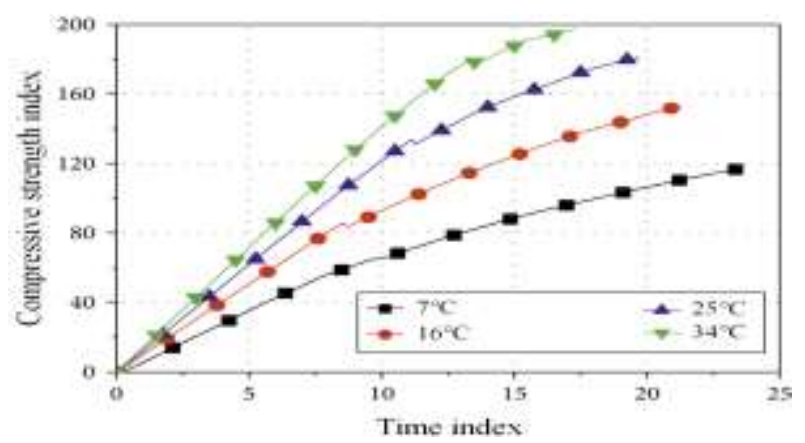

Figure 6 Effect of curing temperature on concrete strength

The quality management of modern engineering projects is different from traditional quality management. In order to determine the circumstances under which the exclusion operation and the attraction operation are performed, a diversity control method based on particle swarm optimization is introduced:

ISSN: 0010-8189

(C) CONVERTER 2020 


$$
\frac{\mathrm{p}}{\mathrm{V}}=\frac{1}{\mathrm{~V}_{\mathrm{m}} \mathrm{a}}+\frac{\mathrm{p}}{\mathrm{V}_{\mathrm{m}}}
$$

Change the position and velocity of each particle according to the following formula:

$$
\mathrm{W}_{\mathrm{i}}=-\Delta \mathrm{G}=\gamma_{\mathrm{g}-\mathrm{s}}-\gamma_{\mathrm{l}-\mathrm{s}}
$$

The choice of parameters in the building layout system is critical to whether the algorithm converges. According to the initial conditions of the building layout, it can be concluded that:

$$
\ln \frac{\mathrm{c}}{\mathrm{c}_{0}}=\frac{1}{\mathrm{RT}} \frac{2 \gamma \mathrm{M}}{\rho \mathrm{R}}
$$

In some cases with special requirements or complex reinforcement, the filling of the concrete mixture determines the quality after hardening. Therefore, a filling inspection is required before pouring. The mass loss rate of concrete under different cycle times is shown in Table 4.

Table 4 Mass loss rate of concrete under different cycle times

\begin{tabular}{|c|c|c|c|c|c|c|c|}
\hline Cycles & 5 times & 20 times & 40 times & 60 times & 80 times & $\begin{array}{c}100 \\
\text { times }\end{array}$ & $\begin{array}{c}120 \\
\text { times }\end{array}$ \\
\hline Loss rate & 0.05 & 0.12 & 0.15 & 0.17 & 0.21 & 0.23 & 0.25 \\
\hline
\end{tabular}

The urban building construction model created by the task based on particle swarm optimization design can advance the design problems and quality problems that may occur in the project in the form of collision detection. The topology reliability optimization simulation is compared as shown in Figure 7.

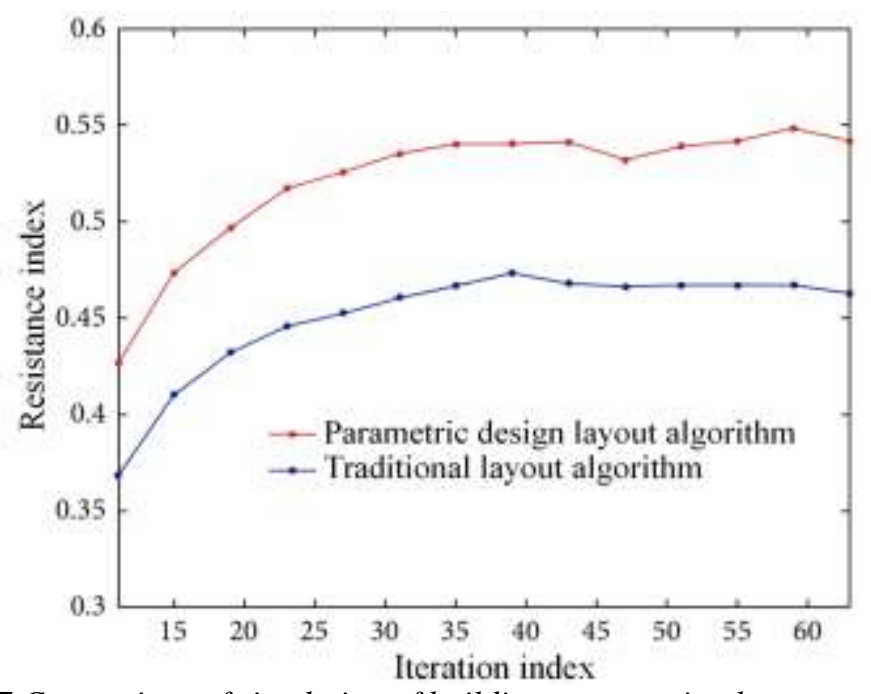

Figure 7 Comparison of simulation of building construction layout optimization

Network planning techniques can be used not only for scheduling, but also for planning optimization, management, and control. The traditional project management theory mainly focuses on the management of individual projects, while the construction under the multi-project environment in actual construction projects is more common. All construction contracting units at all levels must establish a clear schedule management structure. In order to ensure the realization of the target total duration, various measures must be taken to prevent and overcome many factors affecting the progress. There are many reasons for the long duration of the project schedule and its impact on the progress. Some of them have been mastered, and the degree of impact and the possibility of occurrence are estimated based on statistical experience. The control method of project schedule is to decompose the target of the contract time limit layer by layer and to compare and analyze the target value with the actual value under the guidance of the control cycle theory. Getting people involved in planning not only gets their support and motivates them, but also takes into account all the details and influencing factors.

ISSN: 0010-8189 


\section{Conclusions}

Project schedule control is an important part of project management, and a key means to complete project tasks and fulfill contracts to achieve the expected project objectives. The project is a one-time, temporary task, and its results are irreversible once they fail. The precondition of achieving the project schedule target on schedule is to have a scientific and reasonable schedule, which requires project managers to prepare feasible schedule. From the structural adjustment of the enterprise itself to the increasing complexity of the construction project, all of them test the management quality and construction ability of the construction enterprise itself. In the case of resource constraints, the determination of construction priority of project group avoids the delay of key engineering processes and effectively controls the progress of the project. As a kind of plan, the construction schedule is definitely missing the influencing factors. The on-site management personnel still need to strengthen the on-site monitoring and management. We should conduct in-depth and systematic research on China's project management model and organizational environment, and try out a project management operation mechanism that is more suitable for China's national conditions. As one of the project management controls, schedule control cannot consider the progress control as a single consideration, but should consider it comprehensively. This will really achieve the goal of progress control.

\section{Reference}

[1] C. Kim, B. Kim, H. Kim, “4D CAD Model Updating Using Image Processing-Based Construction Progress Monitoring,” Automation in Construction, vol. 35, pp. 44-52, 2013.

[2] C. Kim, H. Son, C. Kim, "Fully automated registration of 3D data to a 3D CAD model for project progress monitoring," Automation in Construction, vol. 35, pp. 587-594, 2013.

[3] Real time progress management: Re-engineering processes for cloud-based BIM in construction, Automation in Construction, 2015, 58:38-47.

[4] L.C. Chao, H.T. Chen, "Predicting project progress via estimation of S-curvel"s key geometric feature values," Automation in Construction, vol. 57, pp. 33-41, 2015.

[5] Guerin, F. Turlough, "Evaluating expected and comparing with observed risks on a large-scale solar photovoltaic construction project: A case for reducing the regulatory burden," Renewable and Sustainable Energy Reviews, vol. 74, pp. 333-348, 2017.

[6] V. Enrique, A. Adán, C. Carlos, "Evolution of RFID Applications in Construction: A Literature Review," Sensors, vol. 15, no. 7, pp. 15988-16008, 2015.

[7] A. Shahi, J.S. West, C.T. Haas, "Onsite 3D marking for construction activity tracking," Automation in Construction, vol. 30, no. 1, pp. 136-143, 2013.

[8] P.P.A. Zanen, "Using 4D CAD to visualize the impacts of highway construction on the public," Automation in Construction, vol. 32, no. 8, pp. 136-144, 2013.

[9] P. Pugnat, R. Barbier, C. Berriaud, et al., "Progress in the Construction of the 43 T Hybrid Magnet at LNCMI-Grenoble," IEEE Transactions on Applied Superconductivity, vol. 28, no. 3, pp. 1-7, 2017.

[10] J. Kim, C. Koo, C.J. Kim, et al., "Integrated CO2, cost, and schedule management system for building construction projects using the earned value management theory," Journal of Cleaner Production, vol. 103, pp. 275-285, 2015.

[11] "A multi-agent model to manage risks in construction project (SMACC)," Automation in Construction, vol. 58, pp. 1-18, 2015.

[12] R. Davies, C. Harty, "Implementing 'Site BIM': A Case Study of ICT Innovation on a Large Hospital Project," Automation in Construction, vol. 30, no. 30, pp. 15-24, 2013.

[13] C. Kim, H. Son, C. Kim, "Automated construction progress measurement using a 4D building information model and 3D data," Automation in Construction, vol. 31, pp. 75-82, 2013.

[14] C. Zhang, D. Arditi, "Automated progress control using laser scanning technology," Automation in Construction, vol. 36(Complete), pp. 108-116, 2013.

[15] Z. Nianmu, Z. Zongliang, Y. Lei, "Study on life-cycle risk management of high earth-rock dam ISSN: 0010-8189 
project," Engineering Sciences, vol. 2013, no. 5, pp. 45-50.

[16] K.K. Han, M. Golparvar-Fard, "Appearance-based material classification for monitoring of operation-level construction progress using 4D BIM and site photologs," Automation in Construction, vol. 53, pp. 44-57, 2015.

[17] R. Maalek, D.D. Lichti, J. Ruwanpura, "Robust Classification and Segmentation of Planar and Linear Features for Construction Site Progress Monitoring and Structural Dimension Compliance Control," Biorheology, vol. II-3/W5, no. 3-4, pp. 129-136, 2015.

[18] Bosché, Frédéric, E. Guenet, "Automating surface flatness control using terrestrial laser scanning and building information models," Automation in Construction, vol. 44, pp. 212-226, 2014.

[19] H. Wang, L. Li, Y.Y. Jiao, et al., "A relationship-based and object-oriented software for monitoring management during geotechnical excavation," Advances in Engineering Software, vol. 71, pp. 34-45, 2014.

[20] H. Xu, J. Feng, S. Li, "Users-orientated evaluation of building information model in the Chinese construction industry," Automation in Construction, vol. 39, no. 4, pp. 32-46, 2014.

[21] H.W. Weijers, W.D. Markiewicz, A.V. Gavrilin, et al., "Progress in the Development and Construction of a 32-T Superconducting Magnet," IEEE Transactions on Applied Superconductivity, vol. 26, no. 4, pp. 1-7, 2016.

[22] A. Martens, M. Vanhoucke, "An empirical validation of the performance of project control tolerance limits," Automation in Construction, vol. 89, pp. 71-85, 2018.

[23] J. Irizarry, E.P. Karan, F. Jalaei, "Integrating BIM and GIS to improve the visual monitoring of construction supply chain management," Automation in Construction, vol. 31, pp.241-254, 2013.

[24] M. Wauters, M. Vanhoucke, "Support Vector Machine Regression for project control forecasting," Automation in Construction, vol. 47, pp. 92-106, 2014.

[25] López-Alonso, Monica, Ibarrondo-Dávila, P. Maria, Rubio-Gámez, C. María, et al., "The impact of health and safety investment on construction company costs, Safety Science,” vol. 60(Complete), pp. 151-159, 2013. 